\title{
ANÁLISE DO PORTAL DE PERIÓDICOS DA UNIVERSIDADE FEDERAL DO RIO GRANDE
}

Angélica Conceição Dias Miranda ${ }^{1^{\star}}$, Adriane Maria Netto de Oliveira ${ }^{1}$, Alessandra Delgado dos Santos ${ }^{1}$, Caio Floriano dos Santos ${ }^{1}$, Gilmar Gomes de Barros ${ }^{1}$, Ingrid Machado Contreira ${ }^{1}$, Josiane Ribeiro Prestes ${ }^{1}$, Luiz Antônio de Almeida Pinto ${ }^{1}$, Simone Machado Firme ${ }^{1}$, Eliezer Mendes ${ }^{1}$

1 Universidade Federal do Rio Grande - Porto Alegre (RS) - Brasil

*Autor correspondente: angelicacdm@gmail.com

\section{Como citar:}

MIRANDA, Angélica C. D. et al.. Análise do portal de periódicos da Universidade Federal do Rio Grande. In: WORKSHOP DE EDITORAÇÃO CIENTÍFICA, 9., 2016, São Paulo. Anais... São Paulo: Associação Brasileira de Editores Científicos, 2016. p. 65-68 DOI: http://dx.doi.org/10.21452/wec.IXwec.2016.0013

\section{INTRODUÇÃO}

A Universidade Federal do Rio Grande (FURG) situa-se na cidade do Rio Grande, no extremo sul do estado do Rio Grande do Sul (RS), tornando-se a mais meridional das universidades públicas brasileiras. Tem seus primórdios na Escola de Engenharia Industrial, fundada em 1955, motivada pela preocupação com a evasão dos jovens da cidade que iam estudar em outras localidades.

Em 1969, já haviam escolas na cidade com cursos de Direito, Filosofia, Pedagogia, Letras e Matemática, além da Engenharia. Assim, foi criada a Fundação Universidade do Rio Grande (FURG), a quem identifica a universidade até hoje. A ação federal de agregação de escolas isoladas em um sistema universitário possibilitou a criação da Universidade, Decreto-Lei no 774 de 20 de agosto de 1969, pelo então presidente da república Costa e Silva.

Nesses 47 anos de existência, a FURG tem crescido no cenário brasileiro de ensino superior, pesquisa e extensão se tornando um catalisador de desenvolvimento, principalmente o social, como apresentado por Novo (2004) em sua dissertação. Para a autora, a FURG apoia o desenvolvimento profissional e de pesquisa, sendo um polo de aperfeiçoamento para o setor produtivo desde a sua criação e de pesquisa, com destaque às questões voltadas à oceanografia.

Em sua pesquisa, Caberlon (2009) relata que a primeira vez que se menciona pesquisa nas atas da universidade data de 1972, pouco após a estruturação da universidade, indicando a preocupação com esse tema, desde os princípios da FURG como universidade. Como resultado com a preocupação com pesquisa, pode-se destacar a criação, em 1976, da Revista Atlântica, primeira da FURG, que ainda está ativa, atualmente em formato digital.

Nesse mesmo alinhamento, com o objetivo de apoiar as revistas da FURG, a PróReitoria de Pesquisa e Graduação (PROPESP) e a Pró-Reitoria de Assuntos Comunitários e Estudantis (PROACE) tomou a iniciativa de criar o Portal de Periódicos da FURG, que hospeda 14 revistas. Procura-se ofertar aos editores da universidade a infraestrutura necessária para a manutenção dos periódicos na forma de um portal integrador. 
Nesse contexto, o presente estudo tem por objetivo apresentar o Portal de Periódicos da FURG, por meio do estudo de quatro revistas oriundas de disciplinas distintas. Com isso, revelar o cenário da publicação na universidade, na medida em que os periódicos científicos são canais importantes na comunicação científica.

\section{METODOLOGIA}

Para realização do estudo foi selecionado quatro periódicos hospedados no Portal de periódicos da FURG, aleatoriamente, desde que não fossem da mesma área. Com isso, optou-se por não direcionar a pesquisa pelos periódicos mais bem avaliados, de forma a ter um cenário mais completo.

Assim, as revistas selecionadas foram: Revista Biblos ${ }^{1}$, Ambiente e Educação $^{2}$, Vitalle - Revista da Ciência da Saúde ${ }^{3}$ e VETOR - Revista de Ciências Exatas e Engenharias ${ }^{4}$. Com isso têm-se revistas diferenciadas, com características diversas, mas todas compartilhando o mesmo ambiente tecnológico, hospedadas em portal desenvolvido com o Open Journal System (OJS), software livre mantido pelo Public Knowledge Project (PKP).

Pelas diferenças entre os periódicos, optou-se pela análise histórica, apresentando as revistas, analisando seus sites e as informações existentes em documentos. Com isso, entende-se cada página da revista como um documento. Métricas como a bibliometria, levantamento de citações, foram utilizadas, para as revistas com maior visibilidade.

\section{RESULTADOS E DISCUSSÃO}

Os periódicos da FURG, mesmo que a considere uma universidade pequena em relação a outras federais, são bem avaliados conforme o estudo de Bueno (2014). A pesquisadora apresentou indícios que a maioria das revistas do portal atende aos critérios de qualidade indicados pela Coordenação de Aperfeiçoamento de Pessoal de Nível Superior (CAPES).

\section{Revista Biblos}

Revista Biblos - Revista do Instituto de Ciências Humanas e da Informação, criada em 1978 ainda no formato impresso, é uma das primeiras revistas científicas da FURG, tendo sido criado pelos cursos de Biblioteconomia e História. Mudou para o formato digital em 2007, integrando o Portal de Periódicos da FURG, em acesso aberto. Em 2009, altera seu foco para as Ciências Humana e Ciência da Informação.

Com o intuito de viabilizar estas publicações, realizaram-se atividades para indexar a revista em bases de dados nacionais e internacionais a partir do ano 2011. Até 2010, a revista não tinha qualis na área da Ciência da Informação. Atualmente a Biblos está indexada em bases nacionais e internacionais como: Base de Dados em Ciência da Informação Acervo de Publicações Brasileiras em Ciência da Informação (BRAPCI), Comissão Nacional de Energia Nuclear (CNEN), Instituto Brasileiro de Informação em Ciência e Tecnologia (lbict), OAlster, Portal da Capes; Sumários.org; Sistema Regional de Información en Línea para Revistas Científicas de América Latina, el Caribe, España y Portugal (Latindex), Directory of Open Access Journals (DOAJ) e Instituto de Investigaciones Bibliotecológicas y de la Información da Universidad Nacional Autónoma de México (INFOBILLA UNAM).

\section{Revista Ambiente \& Educação}

A revista Ambiente \& Educação deu início a publicação em 1996 somente no meio impresso, tendo como escopo principal a educação ambiental e a sustentabilidade. No decorrer de 2008 foi inserida no Portal de periódicos científicos da Universidade Federal do Rio Grande - FURG ${ }^{5}$ com vistas à publicitar suas rotinas

${ }^{1}$ https://www.seer.furg.br/biblos

2 https://www.seer.furg.br/ambeduc

3 https://seer.furg.br/vittalle

4 https://www.seer.furg.br/vetor

5 https://seer.furg.br/ 
editoriais e na busca por maior visibilidade.

Tem periodicidade semestral, disponibiliza 20 volumes, a partir de 2014 passou a ser publicada apenas no formato eletrônico com dois volumes a cada semestre. Encontra-se indexada nas seguintes bases de dados ou plataformas: Biblioteca Virtual da Universidade de São Paulo (USP), Catálogo Coletivo Nacional (CCN), Clustermaps, Livre!, Centro de informações Nucleares, Portal do Sistema Eletrônico de Editoração de Revistas (SEER - IBITC), Latindex, OAlster, PKP e Google acadêmico foi recentemente indexada.

\section{Vittalle: Revista dde Ciências da Saúde (Journal Of Health Sciences)}

A Vittalle: Revista de Ciências da Saúde (Journal of Health Sciences) é um periódico multidisciplinar voltado para pesquisadores e trabalhos da área das Ciências da Saúde, Biológicas, Humanas e outras afins, utilizando metodologias quantitativas e, também, qualitativas. É publicada em meio impresso (ISSN 1413-3563) desde o ano de 1985, inicialmente com o nome "Vittalle - Revista De Ciências Médicas e Biológicas", tendo sido trocado o nome da mesma em 2009 para "Vittalle: Revista De Ciências da Saúde", o qual se mantém até o presente ano. Em 2007 migrou para o meio eletrônico (e-ISSN 2177-7853) passando a fazer parte do Portal de Periódicos Científicos da FURG. Até o ano de 2002 teve publicação anual, após, passou para semestral. Mais tarde, em 2014, voltou para a periodicidade anual. No entanto, em 2017 voltará a ser semestral.

Atualmente, a Vittalle conta com trinta e um volumes (o que corresponde a 31 anos ininterruptos de publicação) e quarenta e três fascículos. Disponibiliza-se online na íntegra nove volumes e dezesseis números via Sistema Eletrônico de Editoração de Revistas (SEER). Em busca de visibilidade, o periódico foi cadastrado nas seguintes bases de dados e diretórios:

\section{A Vetor (Revista de Ciências Exatas e Engenharias)}

A Vetor (Revista de Ciências Exatas e Engenharias) tem como principal foco os trabalhos das áreas de Engenharias, Ciências Exatas e/ou afins. É sediada na Escola Química de alimentos(EQA), na FURG.

O periódico teve seu primeiro número de publicação em 1986, na versão impressa. A partir do volume $1 / 2006$, as rotinas editoriais passaram a ser por meio do SEER. A revista teve publicação anual até 2002, com 12 volumes. Em 2003, passou a ser semestral. A partir desse ano, constam todos os volumes e números no sistema.

Com o objetivo de ampliar o número de acessos à Revista, os editores criaram um perfil no Google Acadêmico, assim, as citações podem ser acompanhadas, bem como o índice h. O trabalho está em fase de implementação. Trata-se de um processo em que os artigos podem ser adicionados tanto em grupos quanto individual e manualmente. Atualmente, foram inseridos 122 artigos. O perfil do Periódico no Google Acadêmico pode ser visualizado na figura 1, juntamente com seu índice de citação.

Figura 1: perfil no google acadêmico da vetor (revista de ciências exatas e engenharias).

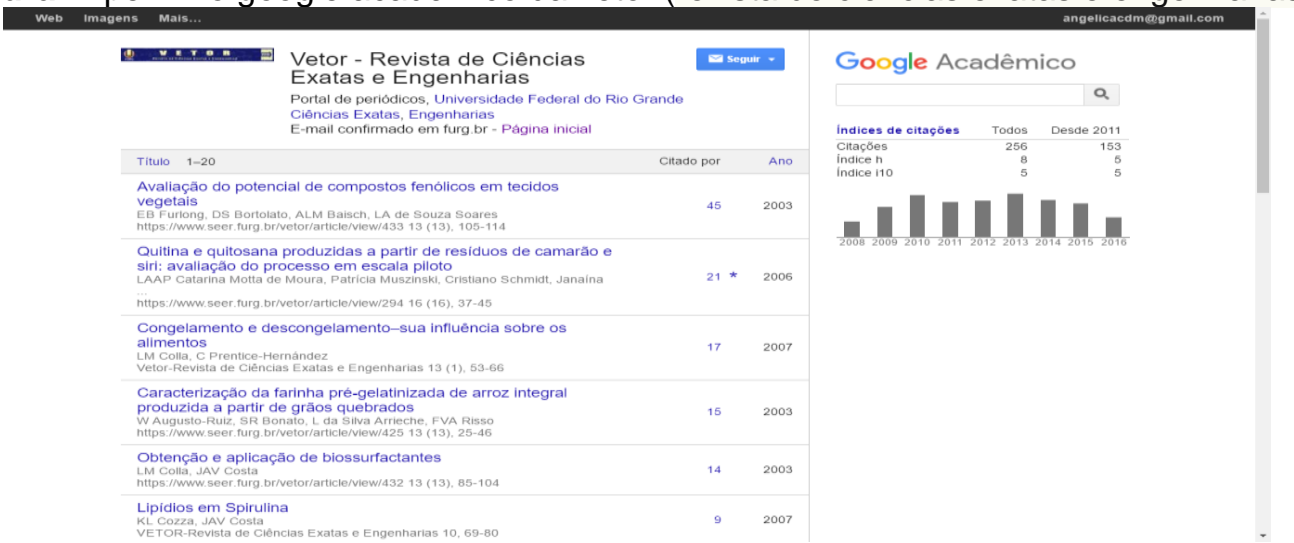

Fonte: google acadêmico: perfil da revista Vetor 


\section{CONSIDERAÇÕES FINAIS}

Pode-se dizer que a pluralidade é o âmago das universidades e essa característica pode ser notada nas suas publicações. Por isso, analisar os portais de periódicos torna-se importante no entendimento da instituição, suas orientações e caminhos traçados. estudos como esse possibilitam levantar as diferenças e desafios em manter canais de comunicação científicas em áreas distintas.

Por isso, o estudo revela as diferenças entres os periódicos analisados, destacando o que é comum nas universidades, à diversidade que faz da universidade um local único, o lócus da coexistência das discussões relativas às diferenças. Apresenta o caminho da FURG na contribuição à ciência, por meio da publicação de revistas científicas.

\section{REFERÊNCIAS}

BRASIL. CÂMARA DOS DEPUTADOS. DECRETO-LEI № 774, DE 20 DE AGOSTO

DE 1969. 1969. Disponível em: <http://www2.camara.leg.br/legin/fed/declei/19601969/decreto-lei-774-20-agosto-1969-374739-publicacaooriginal-1-pe.html>. Acesso em: 15 out. 2016.

BUENO, Cláudia S. G.. Investigação das características de qualidade dos periódicos científicos presentes no portal de periódicos da Universidade Federal do Rio Grande - FURG. 2014. 48 f. TCC (Graduação) - Curso de Biblioteconomia, Instituto de Ciências Humanas e da Informação, Universidade Federal do Rio Grande, Rio Grande, 2014. Disponível em: < http://repositorio.furg.br/handle/1/5700>. Acesso em: 15 out. 2016.

CABERLON, Vera I.. Universidade Federal do Rio Grande: revisando movimentos político-institucionais. Reflexão e Ação, v. 17, n. 2, p. 91-108, 2009. Disponível em: < https://online.unisc.br/seer/index.php/reflex/article/view/1079>. Acesso em: 15 out. 2016.

NOVO, Luciana F.. Importância da FURG no desenvolvimento econômico-social do município do Rio Grande. 2004. 148 f. Dissertação (Mestrado) - Curso de Curso de Pós-graduação em Administração, Centro Socio-econômico, Universidade Federal de Santa Catarina, Florianópolis, 2004. Disponível em:

https://repositorio.ufsc.br/bitstream/handle/123456789/87471/207238.pdf?sequence=1 \&isAllowed=y Acesso em: 15 out. 2016.

PALAVRAS-CHAVE: Portal de Periódicos. Universidade Federal do Rio Grande. 